\title{
Nitric oxide-donating aspirin (NCX 4016) inhibits neointimal thickening in a pig model of saphenous vein- carotid artery interposition grafting: A comparison with aspirin and morpholinosydnonimine (SIN-1)
}

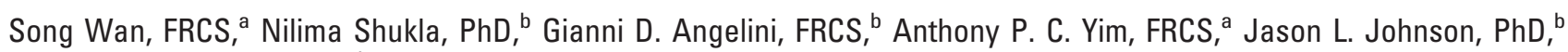
and Jamie Y. Jeremy, $\mathrm{PhD}^{\mathrm{b}}$

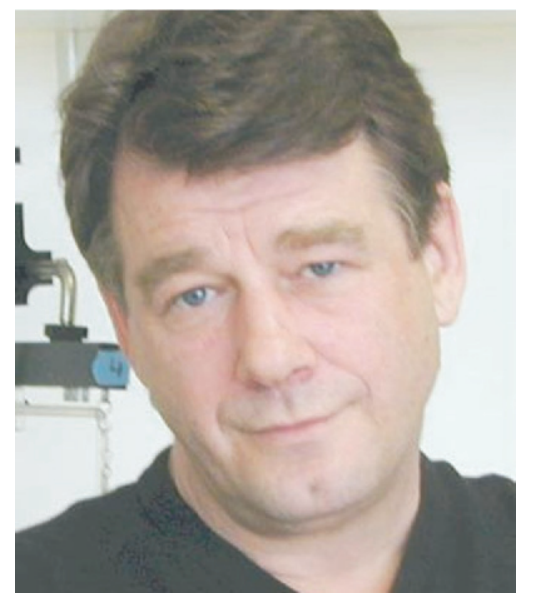

Dr Jeremy
From the Department of Surgery, Prince of Wales Hospital, ${ }^{\text {a }}$ Chinese University of Hong Kong, Hong Kong, China; and The Bristol Heart Institute, ${ }^{\text {b The University of }}$ Bristol, United Kingdom.

Supported by the Chinese University of Hong Kong "RGC Earmarked GrantCUHK 4542/06M," The British Heart Foundation.

Received for publication April 18, 2007; revisions received June 12, 2007; accepted for publication June 15, 2007.

Address for reprints: Jamie Y. Jeremy, $\mathrm{PhD}$, Bristol Heart Institute, Bristol Royal Infirmary, Bristol BS2 8HW, United Kingdom (E-mail: j.y.jeremy@bristol.ac.uk).

J Thorac Cardiovasc Surg 2007;134:1033-9

$0022-5223 / \$ 32.00$

Copyright (C) 2007 by The American Association for Thoracic Surgery

doi:10.1016/j.jtcvs.2007.06.017
Objective: Despite its proven value in reducing thrombotic complications in patients undergoing coronary artery bypass graft surgery, aspirin does not reduce the incidence of late vein graft failure. It was suggested, therefore, that co-administration of nitric oxide with aspirin may compensate for these limitations. A drug class that fulfills this pharmacologic criterion is nitric oxide-donating aspirin (NCX 4016).

Methods: The effect of administration of the aspirin-nitric oxide adduct, NCX 4016, compared with those of aspirin alone and the nitric oxide donor, morpholinosydnonimine, alone (once daily for 1 month) on thickening of saphenous vein-carotid artery interposition grafts was investigated.

Results: NCX 4016, at $10 \mathrm{mg}, 30 \mathrm{mg}$, and $60 \mathrm{mg} \cdot \mathrm{kg}^{-1} \cdot \mathrm{d}^{-1}$, inhibited neointimal thickness and area in porcine vein grafts. Aspirin alone $\left(60 \mathrm{mg} \cdot \mathrm{kg}^{-1} \cdot \mathrm{d}^{-1}\right)$ and morpholinosydnonimine alone $\left(1 \mathrm{mg} \cdot \mathrm{kg}^{-1} \cdot \mathrm{d}^{-1}\right)$, also inhibited neointimal thickness and neointimal area, although they were less potent than NCX 4016. At $30 \mathrm{mg} \cdot \mathrm{kg}^{-1} \cdot \mathrm{d}^{-1}$, aspirin had no effect. Compared with untreated controls, NCX 4016 had little effect on medial thickness or area at $10 \mathrm{mg} / \mathrm{kg}$ or $30 \mathrm{mg} \cdot \mathrm{kg}^{-1} \cdot \mathrm{d}^{-1}$ but had a significant effect at $60 \mathrm{mg} \cdot \mathrm{kg}^{-1} \cdot \mathrm{d}^{-1}$. Aspirin alone and morpholinosydnonimine alone also inhibited medial thickness and area. NCX 4016 at $60 \mathrm{mg} \cdot \mathrm{kg}^{-1} \cdot \mathrm{d}^{-1}$ and aspirin at $60 \mathrm{mg} \cdot \mathrm{kg}^{-1} \cdot \mathrm{d}^{-1}$ increased luminal area.

Conclusions: The range of properties displayed by NCX 4016 (inhibition of neointima formation, gastroprotection, antithrombotic and antiatherogenic effects) renders them potentially useful in treating both early and late vein graft failure and indicates that a clinical study on this novel drug class in patients undergoing coronary bypass grafting is warranted.

$\mathrm{V}$ ein graft thickening and superimposed atherogenesis are the main causes of late failure after coronary artery bypass graft (CABG) surgery with autologous saphenous vein. ${ }^{1}$ Vein graft thickening is determined by increased neointima formation and medial thickening, both of which involve the proliferation and migration of vascular smooth muscle cells (VSMCs). ${ }^{2}$ Superimposed on these rapid events is atherogenesis, which ultimately leads to graft occlusion in as many as $50 \%$ of cases within 10 years. ${ }^{1}$ Although internal thoracic and radial arteries are increasingly being used instead of saphenous vein as a conduit, the percentage of CABG procedures using arteries is still less than $20 \%$ in the United Kingdom. ${ }^{3}$ The saphenous vein will still be widely used in the future for CABG. Apart from aggressive lipid-lowering therapy, ${ }^{4}$ there is no effective therapeutic intervention for late vein graft failure, ${ }^{4}$ which constitutes a considerable clinical problem that needs to be urgently resolved. 


\author{
Abbreviations and Acronyms \\ ASA $=$ aspirin \\ $\mathrm{CABG}=$ coronary artery bypass graft \\ NCX = nitric oxide-donating aspirin \\ $\mathrm{NO}=$ nitric oxide \\ PCNA $=$ proliferating cell nuclear antigen \\ SIN-1 = morpholinosydnonimine \\ $\mathrm{VSMC}=$ vascular smooth muscle cell
}

Aspirin (ASA) is the most widely investigated drug in patients undergoing $\mathrm{CABG}^{5}$ Although ASA reduces the incidence of vein graft thrombosis in both the short and long term, it does not improve vein graft patency between 1 and 3 years after bypass surgery. ${ }^{1,5}$ Because of its antithrombotic effects, however, ASA is routinely administered to patients after $\mathrm{CABG}$ and continued indefinitely thereafter. ${ }^{1,5}$ The relative lack of effect of ASA on late graft failure has been ascribed to minimal effects on VSMC proliferation, atherogenesis, and plaque development, the principal causes of late vein graft failure. ${ }^{1,2,5-7}$ ASA also promotes gastric erosion and ulceration ${ }^{8}$ and inhibits vascular prostacyclin formation. ${ }^{9}$ Furthermore, $5 \%$ to $9 \%$ of patients are "ASA resistant" and 23\% are ASA "semi-responders." 10

In contrast to ASA, nitric oxide (NO) inhibits platelet and leukocyte adhesion and release of mitogens, VSMC proliferation, promotes vasodilation, inhibits neointima formation, and is gastroprotective. ${ }^{11}$ It was suggested, therefore, that the co-administration of an NO donor may compensate for the limitations of ASA. ${ }^{6}$ A novel drug type that intrinsically fulfills this pharmacologic criterion is the group of NO-releasing aspirins (NO-ASA).,12,13 NO-donating aspirins (but not ASA) inhibit the proliferation of VSMCs derived from human saphenous veins and promote relaxation of human isolated saphenous vein. ${ }^{6}$ These effects are mediated through the formation of cyclic guanosine monophosphate, indicating that the active moiety of NO-ASA is NO. ${ }^{7}$ Furthermore, the NO-ASA, NCX 4016, inhibits neointima formation in balloon-injured carotid arteries in the hyperlipidemic mouse. ${ }^{14}$ In man, NCX 4016 inhibits platelet aggregation, releases $\mathrm{NO}$ into the blood for up to 10 hours after administration, reduces blood pressure, and provides gastroprotection. ${ }^{13}$

To determine whether NO-ASA may be of potential benefit in preventing late vein graft failure through an a priori inhibition of neointima formation, we studied the effect of the oral administration of NCX 4016 on neointima formation, medial thickening, and luminal area in saphenous vein-carotid artery interposition grafts 1 month after surgery in the pig. One month is appropriate inasmuch as, in this model, neointima formation is maximal at 1 month after vein implantation and does not increase over ensuing months. ${ }^{15}$ The effect of oral administration of ASA alone and the NO donor morpholinosydnonimine (SIN-1) were also studied because these represent the bioactive moieties of NCX 4016.

\section{Materials and Methods \\ Surgical Procedure}

Studies were performed in 64 male Landrace pigs (8 controls, 56 treated) weighing 30 to $35 \mathrm{~kg}$, which received humane care according to the Home Office Animals Care regulations. Ethical approval had been obtained from the local committee at the University of Bristol. All animals underwent saphenous vein-carotid artery interposition grafting. ${ }^{16,17}$ Anesthesia was induced with ketamine $(30 \mathrm{mg}$ ) and atropine $(0.6 \mathrm{mg})$ administered intramuscularly. After endotracheal intubation, anesthesia was maintained with halothane and oxygen and animals were allowed to ventilate spontaneously throughout. Heparin sodium $(1 \mathrm{mg} / \mathrm{kg}$ ) was administered intravenously, and a single dose of $250 \mathrm{mg}$ of benzyl penicillin was administered intramuscularly before skin incision. A longitudinal incision was made on the outer aspect of the hind limb. Approximately $10 \mathrm{~cm}$ of the vein was then dissected free of surrounding tissue. Care was taken not to remove the adventitia. All side branches were secured with a 6-0 polypropylene ligature (Prolene; Ethicon Inc, Somerville, NJ). The vein was removed from the animal, rinsed in iso-osmotic sodium chloride solution $(0.9 \mathrm{~g} / \mathrm{L})$ containing $2 \mathrm{IU} / \mathrm{mL}$ heparin and $50 \mu \mathrm{g} / \mathrm{mL}$ glyceryl trinitrate, and stored in the same solution at room temperature $\left(23^{\circ} \mathrm{C}\right)$ until needed.

A longitudinal neck incision was made just medial to the sternocleidomastoid muscle, and the common carotid artery was carefully dissected from the internal jugular vein and vagus nerve within the carotid sheath. A 3-cm segment of the common carotid artery was isolated between vascular clamps and excised, beveling the cut ends obliquely to $45^{\circ} \mathrm{C}$. The saphenous vein was cut to the appropriate length, reversed and similarly beveled, and an end-toend anastomosis of the vein to the common carotid artery was carried out with a continuous 7-0 polypropylene suture. Animals were extubated and, when in a satisfactory condition, returned to their pens and fed a normal chow diet.

\section{Drug Administration}

NCX 4016 was supplied by NiCox SA (Nice, France). Nitroaspirins are stable nitrate-ester compounds that require enzymatic hydrolysis to liberate NO. ${ }^{12}$ The kinetics of this metabolic processing leads to durable production of NO released at a constant rate from the site of metabolism. ${ }^{12} \mathrm{NCX} 4016$ (30 and $60 \mathrm{mg}$. $\mathrm{kg}^{-1} \cdot \mathrm{d}^{-1}$ ), aspirin (30 and $60 \mathrm{mg} \cdot \mathrm{kg}^{-1} \cdot \mathrm{d}^{-1}$; Sigma Chemical Co, Poole, Dorset, United Kingdom), or SIN-1 (1 mg $\cdot \mathrm{kg}^{-1} \cdot \mathrm{d}^{-1}$; Sigma) were all fed to pigs ( 8 per treatment group), once daily, incorporated into small amounts of mashed potatoes to ensure complete ingestion of drugs. Drug treatment was commenced 1 day before surgery. Animals were randomized such that surgery was carried out alternately on each dose of drug and drug type. Each graft was removed, including 1-cm segments of the proximal and distal carotid arteries, pressure fixed ex vivo at $100 \mathrm{~mm} \mathrm{Hg}$ with Carson fixative, and postfixed in the same solution for approximately 24 hours before being processed for wax embedding. 

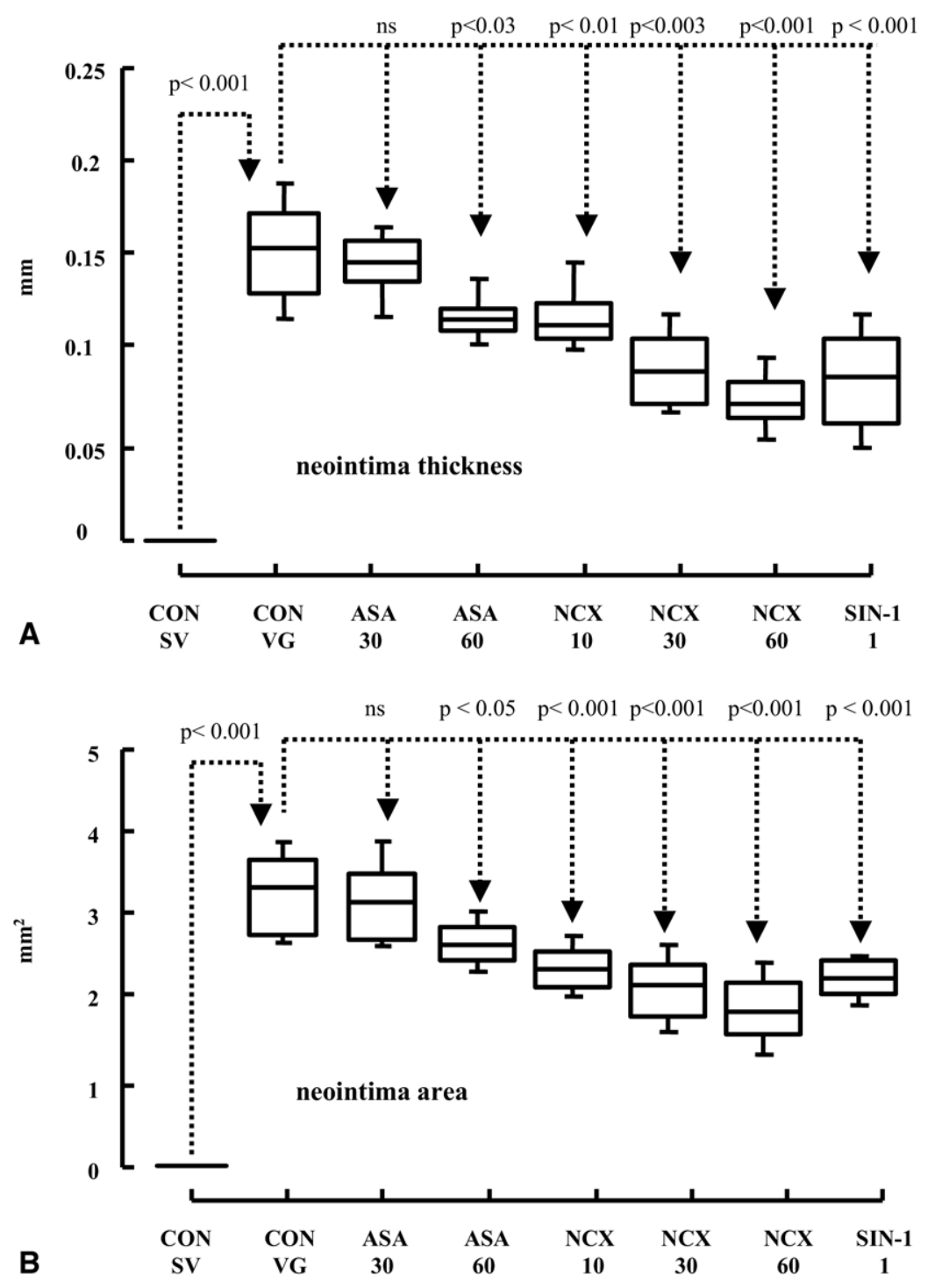

Figure 1. Planimeteric analysis of neointimal thickness (A) and area (B) of vein grafts from pigs to which nitroaspirin 4016 (NCX), aspirin alone (ASA), or morpholinosydnonimine (SIN-1) alone was administered orally, once daily for 1 month. Doses, as milligrams per kilogram per day, are indicated below drug name. Data are expressed as medians and interquartile ranges $(n=8)$. Statistical significance was determined by a Mann-Whitney test with a Bonferroni adjustment. Using the Kendall tau-b test, significant dose-response relationships were obtained for NCX-treated grafts versus controls for both neointimal thickness $(P<.05)$ and neointimal area $(P$ $<.05)$. CON, Control; SV, saphenous vein; VG, vein graft; $n s$, not significant.
Grafts were deemed patent when they had not occluded as a result of thrombosis.

\section{Histologic Analysis}

Histologic studies of vein grafts were carried out as previously described. ${ }^{16,17}$ Sections were dewaxed, rehydrated, and stained with hematoxylin and eosin or Miller elastic van Gieson stain. For proliferating cell nuclear antigen (PCNA), sections were dewaxed, rehydrated, and treated with hydrogen peroxide in methanol to remove endogenous peroxidase, and the following staining was carried out. Sections were microwaved in citrate buffer, quenched in 1:3 horse serum in triethanolamine-buffered saline, and then incubated with PCNA antibody diluted $1: 100$ overnight at $4{ }^{\circ} \mathrm{C}$. Sections were washed and then treated with 1:400 biotinylated goat antimouse antibody followed by streptavidin, biotinylated horseradish peroxidase detection solution. Visualization was achieved with 3,3'-diaminobenzidine; then, after being counter- stained with diluted hematoxylin and eosin, sections were dehydrated and mounted.

\section{Morphometric Analysis}

Vessel wall dimensions were measured by computer-aided planimetry using an Olympus BH-2 microscope with a color video camera head (JVC TK-870E; JVC, Yokohama, Japan) coupled to a Microscale TM/TC image analysis system (Digithurst Ltd, Royston, United Kingdom). The area enclosed by the endothelium and the internal elastic lamina defined the intima, and the area between the internal and external elastic lamina defined the media. Luminal, intimal, and medial perimeters and areas were computed with the luminal boundary and the internal and external elastic lamina as delimiters, and mean values were then calculated for all sections from the same graft. Average intimal, medial, and total vessel wall thickness was derived from the area and perimeter data for 5 sections from 


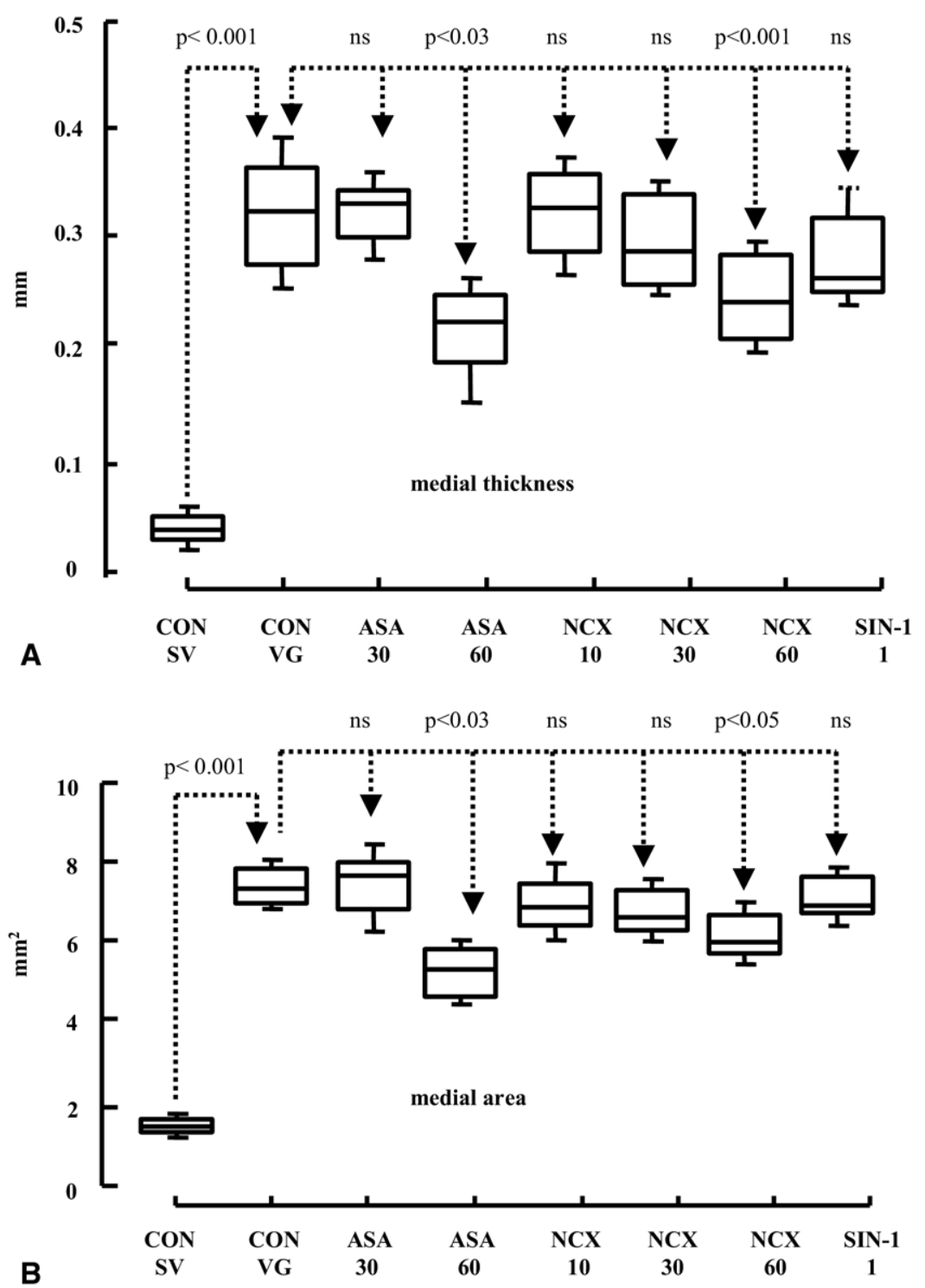

each graft, assuming that the sections consisted of circular profiles, which was a valid assumption because the tissues were fixed at normal perfusion pressure.

\section{Data Analysis and Statistics}

Data were collated and analyzed by Microsoft Excel (Microsoft Corporation, Redmond, Wash) and nonparametric statistical analysis was carried out with an Intercooled Stata 8 statistics package (Stata Corporation, College Station, Tex). The Barlett test for equality of variance (a necessary assumption for a one-way analysis of variance) was significant, indicating that nonparametric methods of analysis were required for morphometric appraisal of vein grafts and PCNA. Thus, values are expressed as median and 25th and 75th interquartile ranges and graphically as box and whisker plots. Mann-Whitney $U$ tests were then applied to test the statistical significance between control and treated groups. To test
Figure 2. Planimeteric analysis of medial thickness (A) and medial area (B) of vein grafts from pigs which nitroaspirin 4016 (NCX), aspirin alone (ASA), or morpholinosydnonimine (SIN-1) alone was administered orally, once daily for 1 month. Doses, as milligrams per kilogram per day, are indicated below drug name. Data are expressed as medians and interquartile ranges

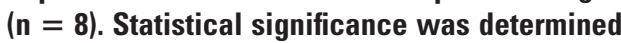
by a Mann-Whitney test with a Bonferroni adjustment. Using the Kendall tau-b test, no significant dose-response relationships were obtained. CON, Control; SV, saphenous vein; VG, vein graft; $n s$, not significant. 


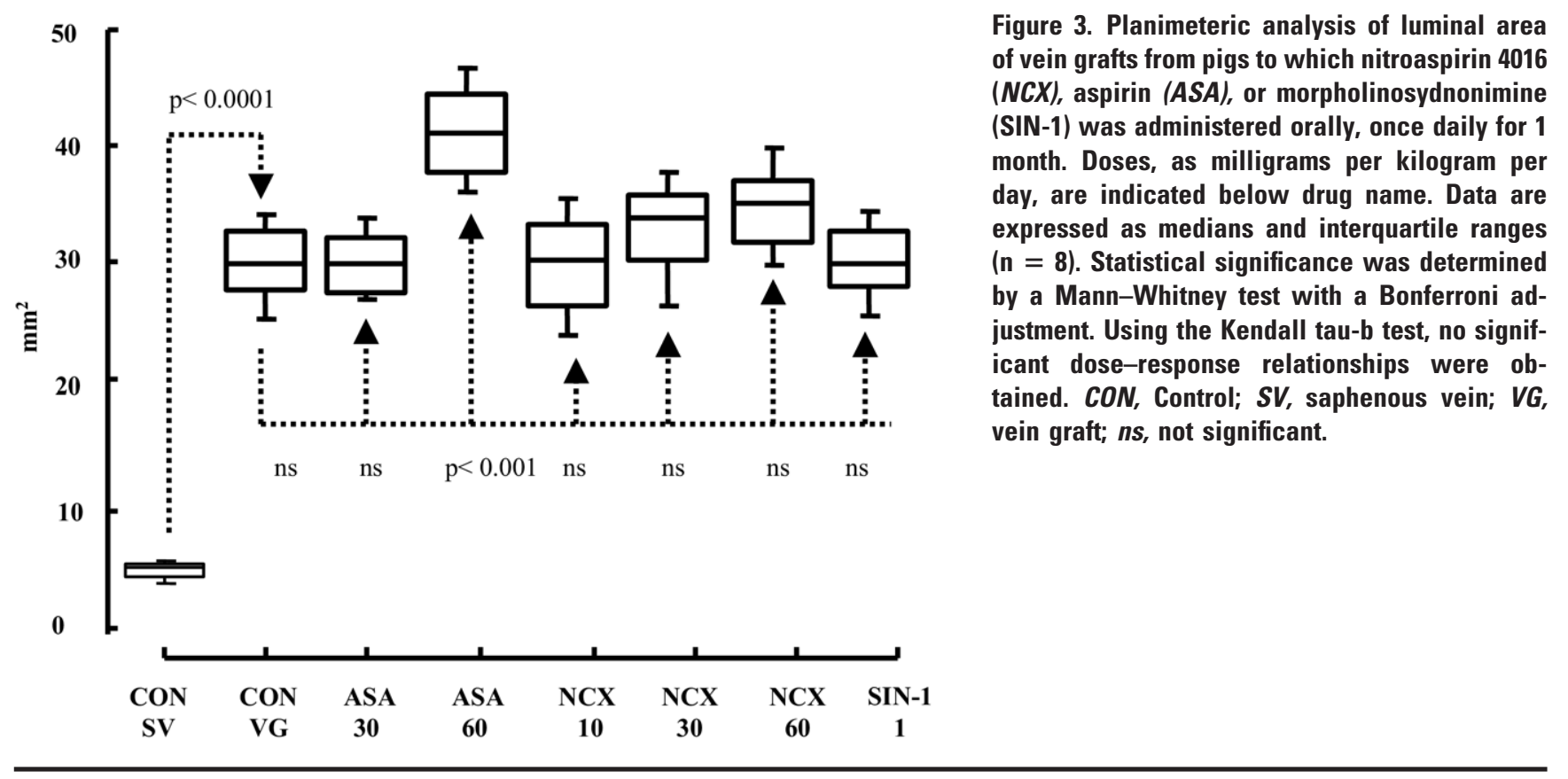

timal thickness and area (Figure 1). By contrast, ASA alone at 30 $\mathrm{mg} \cdot \mathrm{kg}^{-1} \cdot \mathrm{d}^{-1}$ had no effect on neointimal thickness (Figure 1). Compared with untreated controls, administration of NCX 4016 had no significant effect on medial thickness at 10 or 30 $\mathrm{mg} \cdot \mathrm{kg}^{-1} \cdot \mathrm{d}^{-1}$ but had a significant effect at $60 \mathrm{mg} \cdot \mathrm{kg}^{-1}$. $\mathrm{d}^{-1}$ (Figure 2). ASA alone and SIN-1 alone also inhibited medial thickness and area (Figure 2). NCX 4016 and SIN-1 had no significant effect on luminal area, whereas ASA alone at $60 \mathrm{mg} \cdot \mathrm{kg}^{-1} \cdot \mathrm{d}^{-1}$ significantly increased luminal area (Figure 3). Administration of NCX 4016 at 10, 30, and
$60 \mathrm{mg} \cdot \mathrm{kg}^{-1} \cdot \mathrm{d}^{-1}$ and SIN-1 alone $\left(1 \mathrm{mg} \cdot \mathrm{kg}^{-1} \cdot \mathrm{d}^{-1}\right)$ elicited a dose-dependent inhibitory effect on PCNA count (Figure 4). By contrast, ASA alone at 30 and $60 \mathrm{mg} \cdot \mathrm{kg}^{-1} \cdot \mathrm{d}^{-1}$ had no effect on PCNA count (Figure 4).

\section{Discussion}

The present study demonstrates that at doses as low as $10 \mathrm{mg} \cdot \mathrm{kg}^{-1} \cdot \mathrm{d}^{-1}$ for 1 month, NCX 4016 inhibits neointima formation and cell replication in porcine saphenous vein grafts. SIN-1, an NO donor, at $1 \mathrm{mg} \cdot \mathrm{kg}^{-1} \cdot \mathrm{d}^{-1}$,

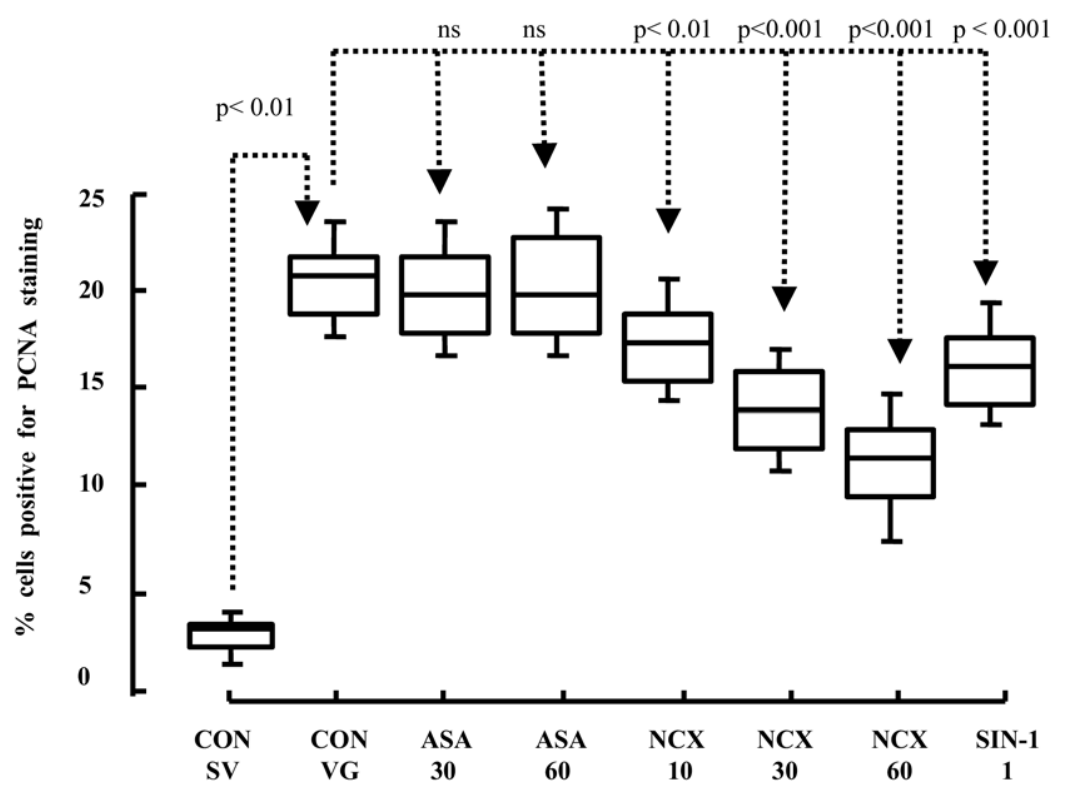

Figure 4. Percentage of cells with proliferating cell nuclear antigen (PCNA)-positive nuclei relative to PCNA-negative nuclei in the intimal/ medial regions of vein grafts from pigs to which nitroaspirin 4016 (NCX), aspirin (ASA), or morpholinosydnonimine (SIN-1) was administered orally, once daily for 1 month. Doses, as milligrams per kilogram per day, are indicated below drug name. Data are expressed as medians and interquartile ranges $(n=8)$. Statistical significance was determined by a Mann-Whitney test with a Bonferroni adjustment. Using the Kendall tau-b test, significant dose-response relationships were obtained for NCX 4016-treated grafts versus controls for luminal area $(P<.05)$. CON, Control; SV, saphenous vein; VG, vein graft; $n s$, not significant. 
also had a marked inhibitory effect on neointima formation. Although ASA also had a significant effect at $60 \mathrm{mg} \cdot \mathrm{kg}^{-1} \cdot \mathrm{d}^{-1}$, it had no effect at $30 \mathrm{mg} \cdot \mathrm{kg}^{-1} \cdot \mathrm{d}^{-1}$ (at which dose NCX 4016 still elicited a marked inhibitory effect on neointimal thickening). The effect of ASA at 60 $\mathrm{mg} \cdot \mathrm{kg}^{-1} \cdot \mathrm{d}^{-1}$ was less than that of NCX 4016 at even 10 $\mathrm{mg} \cdot \mathrm{kg}^{-1} \cdot \mathrm{d}^{-1}$. It is likely, therefore, that the present effect of NCX 4016 on neointima formation is due to the NO moiety of the drug. Indeed, many studies have demonstrated that NO donors or gene transfer of NO synthetase inhibits neointima formation. ${ }^{11}$ Neointima formation involves the migration of VSMCs to the intima. ${ }^{2}$ In turn, NO is a potent inhibitor of VSMC migration, ${ }^{11}$ which would also explain, at least in part, the present inhibitory in vivo effect of NCX 4016 on neointima formation. NCX 4016 elicits effects through both ASA- and NO-mediated mechanisms. These include the inhibition of platelet function, inhibition of neutrophil adherence, a reduction of blood pressure, and gastroprotection. ${ }^{13,18-20}$ In plasma, NCX 4016 releases NO in vivo, assessed as a mixture of nitrites and nitrates, for up to 10 hours after administration. ${ }^{13}$

Other studies on the effect of ASA administration in animal models have yielded equivocal results in that the administration of doses of ASA between 175 and $325 \mathrm{mg} / \mathrm{d}$ either have been shown to inhibit neointima formation ${ }^{21,22}$ or have no effect. ${ }^{23,24}$ Also, ASA does not directly inhibit VSMC proliferation, a central component of neointima formation. ${ }^{7}$ This may indicate that ASA inhibits neointima formation through an inhibition of platelet function. Certainly, platelet adhesion is an immediate consequence of vein graft implantation and, owing to endothelial damage, is highly aggressive. ${ }^{6}$ This can lead to early vein graft failure owing to thrombosis within days after CABG surgery. ${ }^{1,6}$ Platelets release a large number of VSMC mitogens, including serotonin, platelet activating factor, thromboxane $A_{2}$, and peptide growth factors. ${ }^{6}$ It follows, therefore, that the inhibition of platelet adhesion may prevent the local release of these mitogens, which would explain the inhibitory effect of ASA at $60 \mathrm{mg} \cdot \mathrm{kg}^{-1} \cdot \mathrm{d}^{-1}$ on neointima formation. However, at $30 \mathrm{mg} \cdot \mathrm{kg}^{-1} \cdot \mathrm{d}^{-1}$, a dose at which platelet function is almost certain to be inhibited, ASA had no effect on neointima formation. This indicates that platelets do not play a role in mediating neointima formation. One possible explanation for this effect of high-dose ASA is that at high concentrations ASA inhibits signal transduction systems that inhibit cell replication, in particular nuclear factor kappa B. ${ }^{25}$ However, these very high doses of ASA would markedly compromise the well-being of bypass patients through gastric erosion.

A notable finding of the present study was that NCX 4016 and SIN-1 had a minimal effect on medial thickening of porcine vein grafts, whereas ASA at $60 \mathrm{mg} \cdot \mathrm{kg}^{-1} \cdot \mathrm{d}^{-1}$ (but not $30 \mathrm{mg} \cdot \mathrm{kg}^{-1} \cdot \mathrm{d}^{-1}$ ) had a marked inhibitory effect that was reflected by the large increase in luminal area. However, medial thickening is an inevitable and an actually desirable adaptation of a saphenous vein graft anastomosed into coronary arterial beds. ${ }^{26}$ Overdistention by this high dose of ASA may create aneurysmal abnormalities of flow, including vortices and stasis, both of which contribute to thrombogenesis. ${ }^{27,28}$

NCX 4016 possesses antiatherogenic properties, the central long-term lesion in late vein graft failure that is superimposed on the neointima. Most notably, NCX 4016 significantly inhibited macrophage density in injured vessels in a hypercholesterolemic mouse model. ${ }^{14}$ This probably relates to the NO moiety of NCX 4016 inasmuch as NO (but not ASA) inhibits adhesion molecule expression in monocytes. ${ }^{14}$ Other antiatherogenic properties of NCX 4016 include the inhibition of tissue factor expression, superoxide formation, reduced nicotinamide adenine dinucleotide phosphate oxidase expression, cytokine release, and caspase activity, all of which are mediated by the NO moiety of the drug. ${ }^{13,29}$ Thus, NCX 4016 possesses the potential to ameliorate atherogenesis in vein grafts if used over protracted periods.

NCX 4016 also has the additional advantage of being an effective antithrombotic agent through its intrinsic ASA activity. ${ }^{18}$ Certainly, between $3 \%$ and $12 \%$ of saphenous vein grafts occlude, with or without symptoms, within the first month after CABG surgery. ${ }^{1}$ Of course, NO itself is potent inhibitor of platelet activity. ${ }^{6}$ NCX 4016 would prevent gastric erosion associated with long-term administration of ASA. Thus far in all clinical trials reported, NCX 4016 has been shown to elicit minimal side effects. ${ }^{13}$

Thus, given the range of therapeutic properties relevant to vein graft failure and the limitations of ASA, clinical trials on NCX 4016 in patients undergoing CABG are indicated. Although arteries such as internal thoracic and radial are increasingly being used instead of saphenous vein as a conduit, the percentage of CABG operations in which arteries are used is still less $20 \%$ in the United Kingdom; thus, the saphenous vein will still be widely used in the future. From an investigative perspective, effects on graft thickening would be assessed by intravascular ultrasound at 6 months or 1 year after CABG. As mentioned, a significant number of patients are "aspirin resistant" or are semiresponders. ${ }^{10}$ It is possible that NCX 4016 may compensate for this considerable problem inasmuch as $\mathrm{NO}$ also inhibits platelet function. Thus, in a clinical trial, platelet function tests and related thombotic profiles should be assessed before surgery. Effects on oxidative stress, the activity of monocytes (the progentors of plaques), and the activity of neutrophils should also be assessed in such a trial.

We thank Dr Rosemary Greenwood, Bristol Royal Infirmary, for her expert advice on statistics. 


\section{References}

1. Motwani JG, Topol EJ. Aortocoronary saphenous vein graft disease. Pathogenesis, predisposition and prevention. Circulation. 1998;97: 16-31.

2. Jeremy JY, Gadsdon P, Shukla N, Vijayan V, Wyatt M, Newby AC, et al. On the biology of saphenous vein grafts fitted with external synthetic sheaths and stents. Biomaterials. 2007;28:895-908.

3. The Society of Cardiothoracic Surgeons of Great Britain and Ireland National Adult Cardiac Surgical Database Report 2003. Oxfordshire (UK): Dendrite Clinical Systems; 2003.

4. Campeau L. Lipid lowering and coronary bypass graft surgery. Curr Opin Cardiol. 2000;15:395-9.

5. Goldman S, Copeland J, Moritz T, Henderson W, Zadina K, Ovitt T, et al. Long-term graft patency (3 years) after coronary artery surgery. Effects of aspirin: results of a VA Cooperative study. Circulation. 1994;89:1138-43.

6. Jeremy JY, Mehta D, Bryan AJ, Lewis D, Angelini GD. Platelets and saphenous vein graft failure following coronary artery bypass graft surgery. Platelets. 1997;8:295-309.

7. Shukla N, Angelini GD, Wan I, Talpahewa SP, Ascione R, Jeremy JY. Potential role of nitroaspirins in the treatment of vein graft failure. Ann Thorac Surg. 2003;75:1437-42.

8. Jeremy JY, Mikhailidis DP, Dandona P. Effect of nabumetone and its principal active metabolite on in vitro human gastric mucosal and platelet prostanoid synthesis. Br J Rheumatol. 1990;29:116-9.

9. Tsang V, Jeremy JY, Mikhailidis DP, Walesby RK, Wright JV, Dandona $\mathrm{P}$. The release of prostacyclin by the human aorta. Cardiovasc Res. 1988:22:489-93.

10. Gum PA, Kottke-Marchant K, Welsh PA, White J, Topol EJ. A prospective, blinded determination of the natural history of aspirin resistance among stable patients with cardiovascular disease. $J \mathrm{Am}$ Coll Cardiol. 2003;41:961-5.

11. Jeremy JY, Rowe D, Emsley AM, Newby AC. Nitric oxide and vascular smooth muscle cell proliferation. Cardiovasc Res. 1999;43: 658-65.

12. Wallace JL, Muscara MN, de Nucci G, Zamuner S, Cirino G, del Soldato P, et al. Nitric oxide-releasing NSAIDs: GI-safe antithrombotics. Drugs. 1999;2:321-6.

13. Gresele P, Momi S. Pharmacologic profile and therapeutic potential of NCX 4016, a nitric oxide-releasing aspirin, for cardiovascular disorders. Cardiovasc Drug Rev. 2006;24:48-68.

14. Napoli C, Cirino G, Del Soldato P, Sorrentino R, Sica V, Condorelli $M$, et al. Effects of nitric oxide-releasing aspirin versus aspirin on restenosis in hypercholesterolaemic mice. Proc Natl Acad Sci U S A. 2001;98:2860-4.

15. Dashwood MR, Mehta D, Angelini GD, Jeremy JY. Distribution of endothelin-1 $\left(\mathrm{ET}_{\mathrm{A}} / \mathrm{ET}_{\mathrm{B}}\right)$ receptor binding to different regions of porcine interposition venous-arterial grafts. Atherosclerosis. 1998;137: 233-42.
16. Wan S, Yim A, Shukla N, Johnson JL, Angelini GD, Jeremy JY. Orally administered penicillamine is a potent inhibitor of neointimal and medial thickening in porcine saphenous vein grafts. $J$ Thorac Cardiovasc Surg. 2007; 133:494-500.

17. Wan S, Yim A, Bulbulia RA, Johnson JL, Smith FCT, Angelini GD, et al. The endothelin $1_{\mathrm{A}}$ receptor antagonist BSF 302146 is a potent inhibitor of porcine vein graft thickening in vivo. $J$ Thorac Cardiovasc Surg. 2004;27:1317-22.

18. Lechi C, Andrioli G, Gaino S, Tommasoli R, Zuliani V, Ortolani R, et al. The antiplatelet effects of a new derivative of acetylsalicyclic acid - an in vitro study on the early phase of platelet activation and on $\mathrm{TXA}_{2}$ production. Thromb Haemost. 1996;76:791-8.

19. Wallace JL, McKnight W, Wilson TL, del Soldato P, Cirino G. Reduction of shock-induced gastric damage by nitric oxide-releasing aspirin derivative: role of neutrophils. Am J Physiol. 1997;273:G1246-51.

20. Muscara MN, Lovren F, McKnight W, Dicay M, del Soldato P, Triggle CR, et al. Vasorelaxant effects of nitric oxide-releasing aspirin derivative in normotensive and hypertensive rats. $\mathrm{Br} J$ Pharmacol. 2001;133:1314-22.

21. Hirko MK, McShannic JR, Schmidt SP, Sharp WV, Evancho MM, Sims RL, et al. Pharmacologic modulation of intimal hyperplasia in canine vein interposition grafts. J Vasc Surg. 1993;17:877-87.

22. Dobrin PB, Golan J, Fareed J, Blakeman B, Littoy FN. Pre- vs postoperative pharmacologic inhibition of platelets: effect on intimal hyperplasia in canine autogenous vein grafts. J Cardiovasc Surg. 1992;33:705-9.

23. Landymore RW, MacAulay MA, Manku MS. The effects of low, medium and high dose aspirin on intimal proliferation in autologous vein grafts used for arterial reconstruction. Eur J Cardiothorac Surg. 1990;4:441-4.

24. Landymore RW, MacAulay MA, Manku MS. The effects of low, medium and high dose aspirin on intimal proliferation in autologous vein grafts used for arterial reconstruction. Eur J Cardiothorac Surg. 1990;4:441-4.

25. Frantz B, O'Neill EA. The effect of sodium salicylate and aspirin on NF-kappa B. Science. 1995;270:2017-9.

26. Mehta D, George SJ, Jeremy JY, Izzat MB, Southgate KM, Bryan AJ, et al. External stenting reduces long-term medial and neointimal thickening and platelet derived growth factor expression in a pig model of arteriovenous bypass grafting. Nat Med. 1998;4:235-9.

27. Dobrin PB. Mechanical forces associated with the development of intimal hyperplasia with respect to vascular grafts. In: Dobrin PB, editor. Intimal hyperplasia. Austin: RG Landes; 1994. p. 85-109.

28. Caro C, Jeremy JY, Watkins N, Bulbulia R, Angelini GD, Smith F, et al. Geometry of unstented and stented pig common carotid artery bypass grafts. Biorheology. 2002;39:507-12.

29. Muzaffar S, Shukla N, Angelini GD, Jeremy JY. Nitroaspirins and morpholinosydnonimine, but not aspirin, inhibit the formation of superoxide and the expression of gp91 $1^{\text {phox }}$ induced by endotoxin and cytokines in pig pulmonary artery vascular smooth muscle cells and endothelial cells. Circulation. 2004;110:1140-7. 